\title{
APLIKASI MOBILE AUGMENTED REALITY BERBASIS VUFORIA DAN UNITY PADA PENGENALAN OBJEK 3D DENGAN STUDI KASUS GEDUNG M UNIVERSITAS SEMARANG
}

\author{
Atmoko Nugroho, Basworo Ardi Pramono \\ Program Studi Teknik Informatika \\ Fakultas Teknologi Informasi dan Komunikasi \\ Universitas Semarang \\ atmoko@usm.ac.id,basworo@usm.ac.id
}

\begin{abstract}
Realitas tertambah, atau kadang dikenal dengan singkatan bahasa Inggrisnya AR (augmented reality), adalah teknologi yang menggabungkan benda maya dua dimensi dan ataupun tiga dimensi ke dalam sebuah lingkungan nyata tiga dimensi lalu memproyeksikan benda-benda maya tersebut dalam waktu nyata. Tidak seperti realitas maya yang sepenuhnya menggantikan kenyataan, realitas tertambah sekedar menambahkan atau melengkapi kenyataan.

Penelitian ini menggunakan metode pengembangan sistem waterfall, dimana alur penelitian akan mengikuti fase - fase yang ada di waterfall. Aplikasi ini akan dibangun dengan menggunakan Unity3D dan Vuforia.

Tujuan dari penelitian ini adalah menghasilkan suatu aplikasi bantu pembelajaran untuk memudahkan mahasiswa dalam memahami materi augmented reality melalui perangkat mobile. Sehingga mahasiswa juga dapat memahami bagaimana mobile augmented reality dapat membantu mahasiswa melihat secara nyata objek 3D secara interaktif.
\end{abstract}

Keyword: augmented reality, mobile, $3 d$ object.

\section{PENDAHULUAN}

\subsection{Latar Belakang}

Realitas tertambah, atau kadang dikenal dengan singkatan bahasa Inggrisnya AR (augmented reality), adalah teknologi yang menggabungkan benda maya dua dimensi dan ataupun tiga dimensi ke dalam sebuah lingkungan nyata tiga dimensi lalu memproyeksikan benda-benda maya tersebut dalam waktu nyata. Tidak seperti realitas maya yang sepenuhnya menggantikan kenyataan, realitas tertambah sekedar menambahkan atau melengkapi kenyataan. Benda-benda maya menampilkan informasi yang tidak dapat diterima oleh pengguna dengan inderanya sendiri. Hal ini membuat realitas tertambah sesuai sebagai alat untuk membantu persepsi dan interaksi penggunanya dengan dunia nyata. Informasi yang ditampilkan oleh benda maya membantu pengguna melaksanakan kegiatan-kegiatan dalam dunia nyata. Selain digunakan dalam bidang-bidang seperti kesehatan, militer, industri manufaktur, realitas tertambah juga telah diaplikasikan dalam perangkat-perangkat yang digunakan orang banyak, seperti pada telepon genggam. Peneliti merasakan pentingnya materi object 3D dalam mata kuliah Simulasi dan Game sebagai dasar bagi mahasiswa teknik Informatika agar mudah memahami bagaimana sebuah Objek 3D mempunyai kordinat sumbu kartesius .Sementara itu dari pengalaman peneliti selama mengampu mata kuliah Simulasi dan Game ini, sebagian besar mahasiswa menemui kesulitan memahami koordinat kartesius 3D yang diberikan oleh Dosen. Dari permasalahan tersebut, maka peneliti tertarik untuk membuat suatu aplikasi Augmented Reality berbasis mobile yang ditujukan untuk membantu mahasiswa agar lebih mudah dalam memahami materi Objek 3D, selain itu juga sebagai sarana peneliti untuk menyajikan materi 3D object dalam bentuk yang lebih interakif

\subsection{Batasan masalah}

Penelitian ini memiliki beberapa batasan masalah yaitu: a. Penelitian ini menggunakan 1 (satu) objek 3Dimensi.

\subsection{Perumusan Masalah}

Dari latar belakang di atas maka perumusan masalah dalam penelitian ini yaitu: 2 Suatu aplikasi Augmented Reality berbasis mobile yang ditujukan untuk membantu mahasiswa agar lebih mudah dalam memahami materi Objek 3D, selain itu juga sebagai sarana peneliti untuk menyajikan materi 3D object dalam bentuk yang lebih interakif.

\subsection{Tujuan Penelitian}

Peneliti merasakan pentingnya materi object 3D dalam mata kuliah Simulasi dan Game sebagai dasar bagi mahasiswa teknik Informatika agar mudah memahami bagaimana sebuah Objek 3D mempunyai kordinat sumbu kartesius.

\subsection{Luaran Penelitian}

Luaran dari penelitian ini berupa aplikasi Augmented reality dengan menggunakan Gedung $M$ sebagai objek nya.

\section{TINJAUAN PUSTAKA}

\subsection{Konsep Dasar}

a. Konsep Dasar Grafis Grafik adalah karangan visual yang dapat memberi satu atau lebih keterangan visual. Grafik ini bisa juga diartikan sebagai kombinasi dari gambar-gambar, lambang-lambang, simbol-simbol, huruf, angka, kata, lukisan, sketsa yang dijadikan satu kategori untuk memberikan konsep dan juga ide dari pengirim kepada sasarannya dalam menyampaikan informasi.

b. Konsep Dasar Pemodelan Pemodelan adalah membentuk suatu benda-benda atau obyek. Membuat 
dan mendesain obyek tersebut sehingga terlihat seperti hidup. Sesuai dengan obyek dan basisnya, proses ini secara keseluruhan dikerjakan di komputer. Melalui konsep dan proses desain, keseluruhan obyek bisa diperlihatkan secara 3 dimensi, sehingga banyak yang menyebut hasil ini sebagai pemodelan 3 dimensi (3D modelling) (Nalwan, 1998). Ada beberapa aspek yang harus dipertimbangkan bila membangun model obyek, kesemuanya memberi kontribusi pada kualitas hasil akhir. Hal-hal tersebut meliputi metoda untuk mendapatkan atau membuat data yang mendeskripsikan obyek, tujuan dari model, tingkat kerumitan, perhitungan biaya, kesesuaian dan kenyamanan, serta kemudahan manipulasi model. Proses pemodelan 3D membutuhkan perancangan yang dibagi dengan beberapa tahapan untuk pembentukannya. Seperti obyek apa yang ingin dibentuk sebagai obyek dasar, metoda pemodelan obyek 3D, pencahayaan dan animasi gerakan obyek sesuai dengan urutan proses yang akan dilakukan. Aplikasi grafik 3 dimensi (3D) adalah perangkat lunak yang digunakan untuk membuat, mengedit, dan memanipulasi informasi dalam bentuk gambar 3 dimensi. Berbeda dengan format gambar atau image secara umum adalah dalam bentuk 2 dimensi. 1. 3D Studio Max, bersifat komersial dan diproduksi oleh Autodesk. 2. Silo 3D Modelling, bersifat komersial dan diproduksi oleh Nevercenter Ltd. Co. 3. Maya, bersifat komersial dan diproduksi oleh Alias Systems Corp 4

c. Desain Pemodelan Grafis adalah suatu ilmu yang mempelajari tentang membuat dan menciptakan obyek baru berupa seni terapan, arsitektur, dan berbagai pencapaian kreatif lainnya yang direkayasa perangkat lunak merupakan suatu hal yang dilakukan di tahapan awal untuk pembuatan, penyimpanan, dan manipulasi model dan citra.

\subsection{Pengertian 3D}

3D atau 3 Dimensi adalah sebuah objek atau ruang yang memiliki panjang, lebar, dan tinggi yang memiliki bentuk. Konsep tiga dimensi menunjukan sebuah objek atau ruang yang memiliki tiga dimensi geometris terdiri dari; kedalaman, lebar, dan tinggi. Konsep tiga dimensi atau 3D menunjukkan sebuah objek atau ruang memiliki tiga dimensi geometris yang terdiri dari: kedalaman, lebar dan tinggi. Contoh tiga dimensi suatu objek / benda adalah bola, piramida atau benda spasial seperti kotak sepatu. Karakteristik 3D mengacu pada tiga dimensi spasial, bahwa 3D menunjukkan suatu titik koordinat Cartesian X, Y dan Z.

Penggunaan istilah 3D ini dapat digunakan di berbagai bidang dan sering dikaitkan dengan hal-hal lain seperti spesifikasi kualitatif tambahan (misalnya: grafis tiga dimensi, 3D video, film 3D, kacamata 3D, suara 3D). Kemajuan dunia computer grafik khususnya 3D telah berkembang dengan sangat pesat saat ini. Telah banyak kemudahan-kemudahan dan feature-feature baru yang dikeluarkan oleh pihak vendor dalam upaya untuk semakin memikat konsumen dengan produk mereka.

\subsection{Unity}

Aplikasi unity 3D adalah game engine merupakan sebuah software pengolah gambar, grafik, suara, input, dan lain-lain yang ditujukan untuk membuat suatu game, meskipun tidak selamanya harus untuk game. Contohnya adalah seperti materi pembelajaran untuk simulasi membuat SIM. Kelebihan dari game engine ini adalah bisa membuat game berbasis 3D maupun 2D, dan sangat mudah digunakan.

Unity merupakan game engine yang ber-multiplatform. Unity mampu di publish menjadi Standalone (.exe), berbasis web, berbasis web, Android, IoS Iphone, XBOX, dan PS3. Walau bisa dipublish ke berbagai platform, Unity perlu lisensi untuk dapat dipublish ke platform tertentu. Tetapi Unity menyediakan untuk free user dan bisa di publish dalam bentuk Standalone (.exe) dan web. Untuk saat ini Unity sedang di kembangkan berbasis AR (Augment Reality). Untuk mengaktifkan lisensi, Unity perlu adanya lisensi. Sebagai contoh ketika ingin mengaktifkan free user, langkah pertama adalah mendownload softwarenya secara gratis pada web www.unity3d.com.

Setelah selasai instalasi, maka Unity meminta untuk 5 terhubung dengan internet untuk aktifasinya. Lalu selesai unity akan automatis run ke program. Untuk langkah selanjutnya Unity tidak perlu lagi memerlukan koneksi internet saat menjalankan aplikasinya. Unity bukan software game engine baru, sehingga banyak tutorial yang tersebar luas, bahkan banyak game dan tutorial untuk Unity yang telah beredar. Unity cepat berkembang dikarenakan bisa free user dan banyak di implementasikan ke berbagai platform disamping banyaknya tutorial yang bisa dengan mudah dicari. Dengan Unity3D kita dapat membuat game 3D, FPS dan 2D game bahkan Game Online, fitur lain tentang Unity berikut selengkapnya : 1. Membuat Game 2D / 3D. 2. Membuat Game FPS, Simulasi dan Aplikasi Augmented Reality. 3. Membuat Game Online. 4. Dukungan Konversi : Mobile Android, Iphone, Blackberry, Windows, Linux, Flash, Webplayer. 5. Online Publish Google Play, Android market. 6. Dukungan kode : C\#, Javascript dan Boo. 7. Dukungan Extensi file, 3ds, obj, fbx.

\subsection{Vuforia}

Vuforia adalah Augmented Reality Software Development Kit (SDK) untuk perangkat mobile yang memungkinkan pembuatan aplikasi AR. SDK Vuforia juga tersedia untuk digabungkan dengan Unity yaitu bernama Vuforia AR Extension for Unity. Vuforia merupakan SDK yang disediakan oleh Qualcomm untuk membantu para developer membuat aplikasi-aplikasi Augmented Reality (AR) di mobile phones (iOS, Android). SDK Vuforia sudah sukses dipakai di beberapa aplikasi-aplikasi mobile untuk kedua platform tersebut. 
AR Vuforia memberikan cara berinteraksi yang memanfaatkan kamera pada mobile phones untuk digunakan sebagai perangkat masukan, sebagai mata elektronik yang mengenali penanda tertentu, sehingga di layar bisa ditampilkan perpaduan antara dunia nyata dan dunia yang digambar oleh aplikasi. Dengan kata lain, Vuforia adalah SDK untuk computer vision based AR.

\subsection{Augmented Reality}

Ronald T. Azuma (2008) mendefinisikan augmented reality sebagai penggabungan benda-benda nyata dan maya di lingkungan nyata, berjalan secara interaktif dalam waktu nyata, dan terdapat integrasi antarbenda dalam tiga dimensi, yaitu benda maya terintegrasi dalam dunia nyata.

Penggabungan benda nyata dan maya dimungkinkan dengan teknologi 6 tampilan yang sesuai, interaktivitas dimungkinkan melalui perangkat-perangkat input tertentu, dan integrasi yang baik memerlukan penjejakan yang efektif. Sedangkan menurut Stephen Cawood \& Mark Fiala dalam bukunya yang berjudul Augmented reality: a practical guide, mendefinisikan bahwa Augmented Reality merupakan cara 6 alami untuk mengeksplorasi objek 3D dan data, AR merupakan suatu konsep perpaduan antara virtualreality dengan world reality. Sehingga objek objek virtual 2 Dimensi (2D) atau 3 Dimensi (3D) seolah-olah terlihat nyata dan menyatu dengan dunia nyata. Pada teknologi AR, pengguna dapat melihat dunia nyata yang ada di sekelilingnya dengan penambahan obyek virtual yang dihasilkan oleh komputer.

\section{METODE PENELITIAN}

\subsection{Metode Pengumpulan Data}

Metode pengumpulan data yang dilakukan dalam penelitian ini adalah :

1. Observasi: Mengamati kebutuhan user (pengguna) yang akan menggunakan aplikasi Augmented Reality berbasis Mobile sebagai alat bantu pembelajaran materi pengenalan objek 3D dalam mata kuliah Simulasi dan Game.

2. Studi Pustaka : Mengumpulan literatur pendukung penelitian, baik dari buku referensi ataupun dari browsing internet.

\subsection{Metode Pengembangan Sistem}

Metode pengembangan sistem yang digunakan adalah model waterfall (Al Bahra Bin Ladjamudin, 2010) yang mempunyai tahapan-tahapan:

\section{a. Analisa Kebutuhan}

Merancang kebutuhan minimum perangkat keras dan perangkat lunak yang dipakai dalam membuat program.

b. Perancangan Sistem

Desain sistem membagi proses dari kebutuhan yang diperlukan ke salah satu perangkat keras atau perangkat lunak. Desain sistem menetapkan arsitektur sistem secara menyeluruh. Desain perangkat lunak melibatkan pengidentifikasian dan pendeskripsian dari sistem beserta relasinya.

c. Implementasi

Desain dari sistem perangkat lunak diterapkan menjadi suatu aplikasi Augmented Reality berbasis Mobile.

d. Pengujian

Unit program atau program diintegrasikan dan diuji sebagai satu sistem aplikasi Augmented Reality berbasis Mobile untuk memastikan bahwa seluruh kebutuhan perangkat lunak dan perangkat keras telah terpenuhi setelah pengujian sistem diberikan kepada pengguna dengan menggunakan pengujian perangkat lunak yaitu Black Box dan White Box sehingga dapat dilakukan perbaikan agar sistem dapat dimanfaatkan secara maksimal sesuai dengan tujuan pembuatan sistem.

e. Penggunaan dan Pemeliharaan

Instalasi dan pemeliharaan sistem hardware dan software dilakukan untuk mengembangkan implementasi dari unit sistem. Software yang digunakan untuk mengembangkan aplikasi Augmented Reality berbasis Mobile adalah Unity3D dan Vuforia.

\section{HASIL DAN PEMBAHASAN}

\subsection{Analisa System}

Analisis sistem bertujuan untuk memahami masalah yang sedang dihadapi dengan sistem yang ada saat ini, sehingga diharapkan dengan mengetahui masalah-masalah tersebut, kita bisa merancang suatu sistem baru yang akan menyelesaikan atau paling tidak mengurangi masalahmasalah yang ada. Analisis sistem ini nantinya akan memeriksa requirements apa yang harus dipenuhi oleh sistem baru yang akan dibangun tersebut.

Kebutuhan hardware:
a) Prosessor : Intel Pentium i5
b) VGA : NVIDIA Geforce 610M 2GB
c) Memori $: 8 \mathrm{~GB}$

Kebutuhan Software:

a) Game Engine Unity IDE versi 5.2.2

b) vuforia-unity-6-0-17.unitypackage

c) Microsoft windows 8.1

\subsection{Desain System}

a. Desain model 3D 


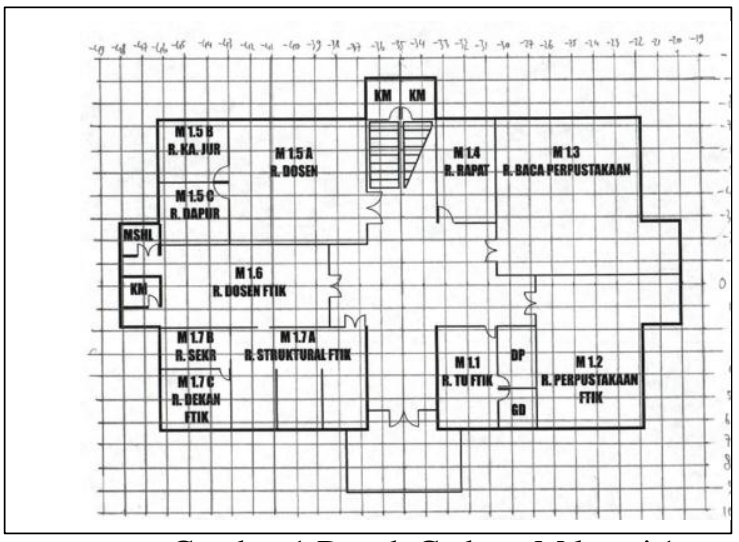

Gambar 1 Denah Gedung M lantai 1

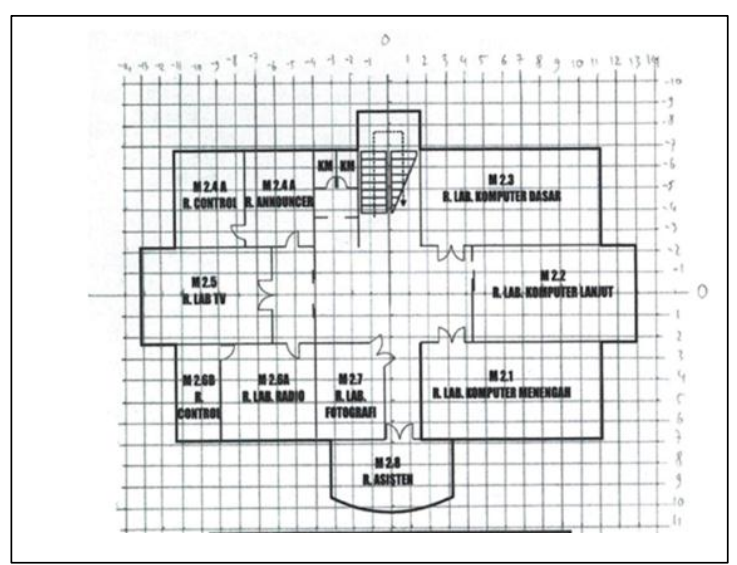

Gambar 2 Denah Gedung M lantai 2

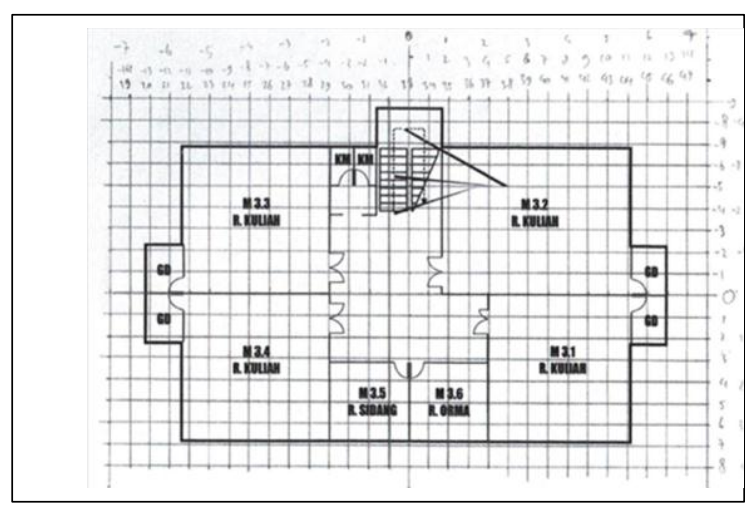

Gambar 3 Denah Gedung M lantai 3

b. Desain Flowcart Aplikasi

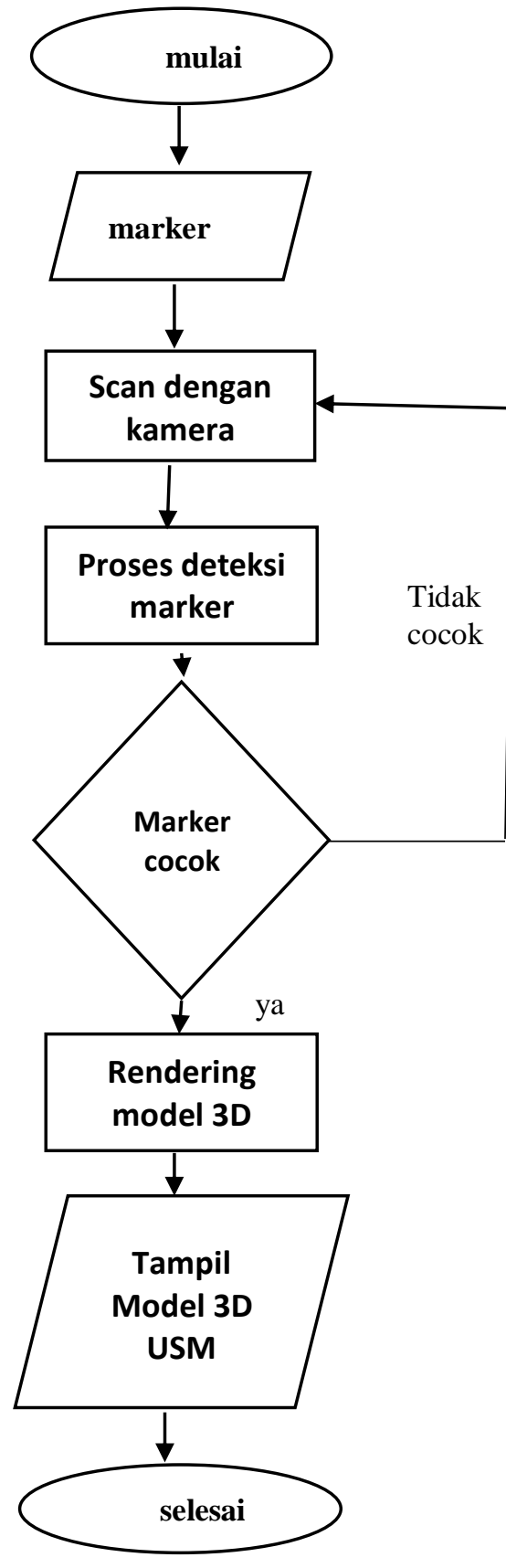

Gambar 4 Desain Flowcart Aplikasi

\subsection{Implementasi}

Aplikasi ini dibangun sebagai alat untuk menampilkan model 3D Gedung M Universitas semarang, bentuk gedung dan lantai ruangan secara 3D, dimana bentuk 3D ini akan ditampilkan pada sebuah marker atau gambar yang sudah ditandai.. 

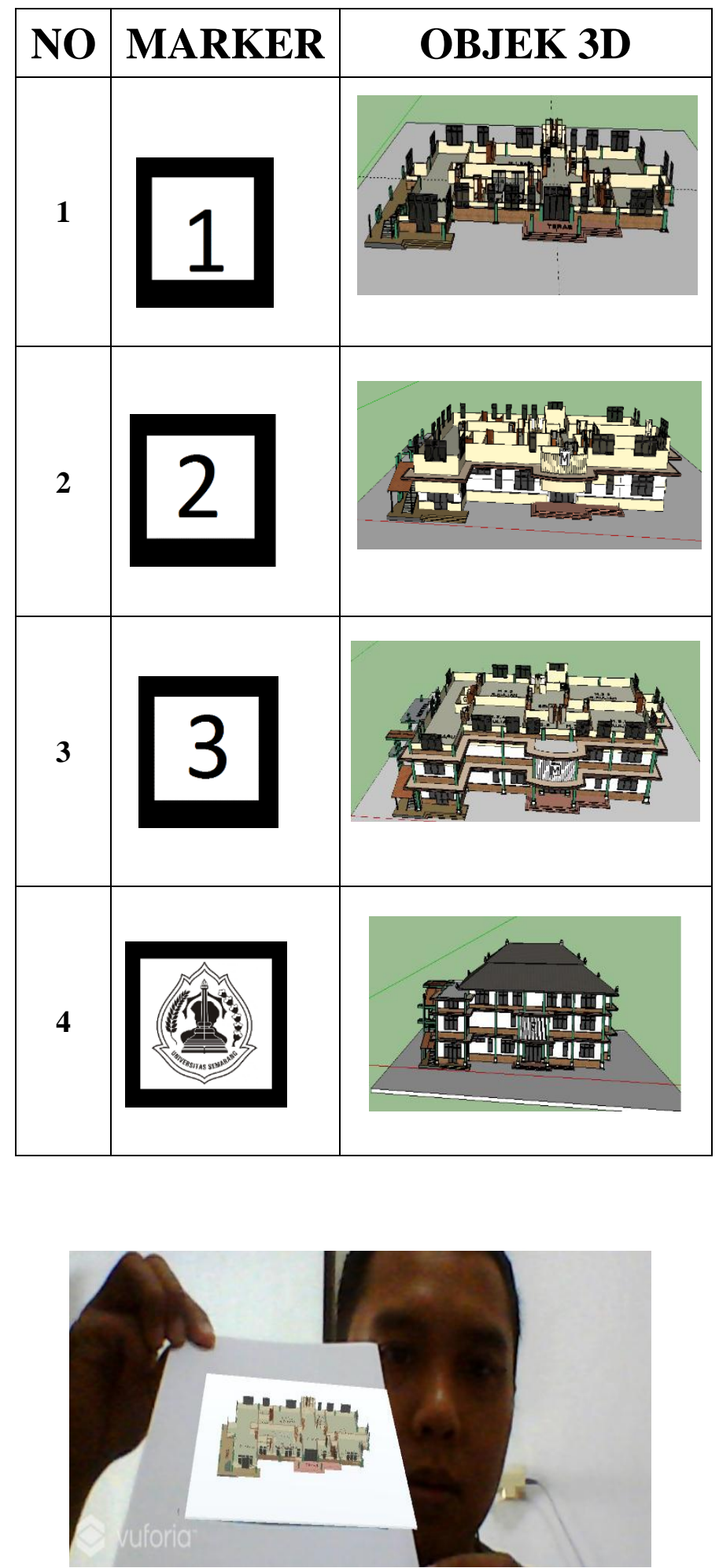

Gambar 5 Aplikasi 1 dengan model 3D.

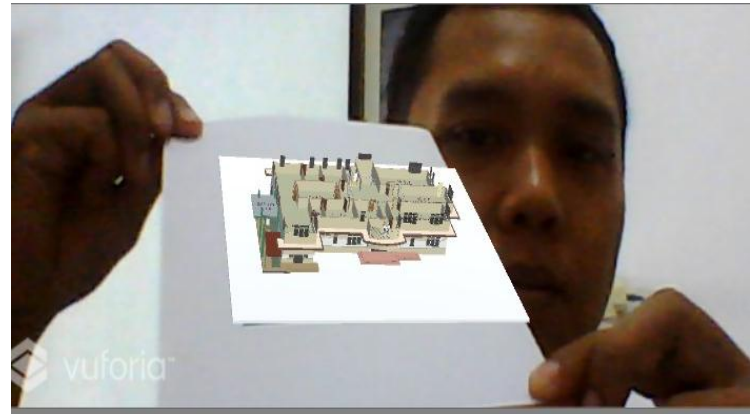

Gambar 6 Aplikasi 2 dengan Model 3D

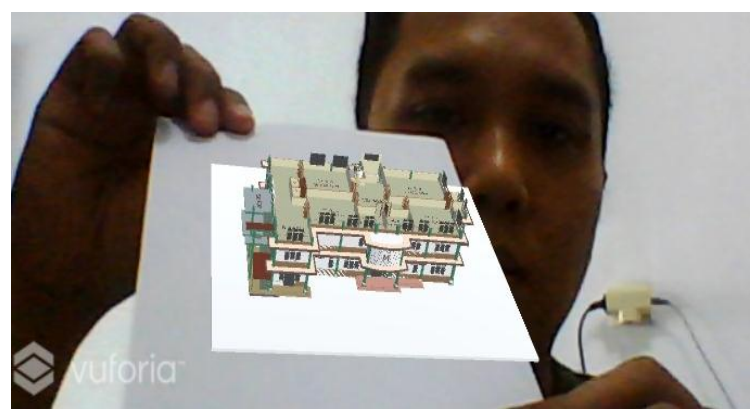

Gambar 7 Aplikasi 3 dengan Model 3D

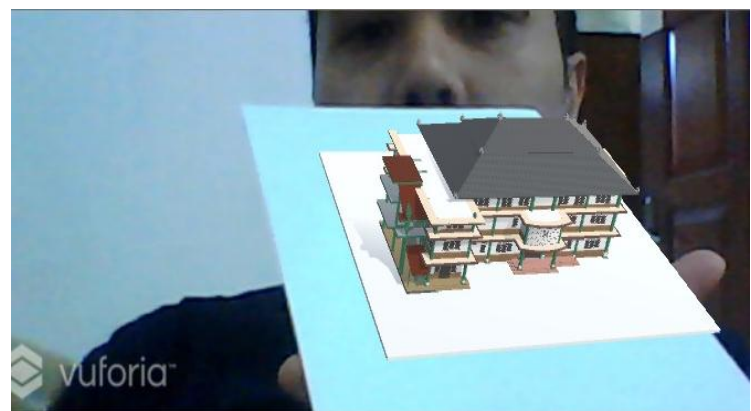

Gambar 8 Aplikasi 4 dengan Model 3D

4.4 Pengujian Sistem

Tabel 4.2 Pengujian Sistem

\begin{tabular}{|c|l|l|l|}
\hline No & \multicolumn{1}{|c|}{ Pengujian } & \multicolumn{1}{|c|}{ Proses } & Hasil \\
\hline $\mathbf{1}$ & Install APK & $\begin{array}{l}\text { Proses instalasi } \\
\text { terpasang pada } \\
\text { smartphone } \\
\text { android dengan } \\
\text { baik }\end{array}$ & Berhasil \\
\hline $\mathbf{2}$ & $\begin{array}{l}\text { Menjalankan } \\
\text { aplikasi }\end{array}$ & $\begin{array}{l}\text { Berjalan baik } \\
\text { dan terbuka }\end{array}$ & Berhasil \\
\hline $\mathbf{3}$ & $\begin{array}{l}\text { Deteksi marker } \\
\text { yang sesuai }\end{array}$ & $\begin{array}{l}\text { Objek muncul } \\
\text { sesuai marker }\end{array}$ & Berhasil \\
\hline $\mathbf{4}$ & $\begin{array}{l}\text { Deteksi marker } \\
\text { berbeda dan } \\
\text { tidak sesuai }\end{array}$ & $\begin{array}{l}\text { objek tidak } \\
\text { muncul }\end{array}$ & Berhasil \\
\hline
\end{tabular}




\subsection{Perawatan Sistem}

Pada tahapan ini dilakukan monitoring proses, evaluasi dan perubahan/ perbaikan apabila diperlukan. Perawatan software: Update software unity dan vuforia

\section{KESIMPULAN}

Berdasarkan Analisa dan pengujian pada aplikasi ini dapat disimpulkan.

a. Pemanfaatan teknologi Augmented Reality dengan mengunakan unity 3d dan vuforia berhasil dilakukan.

b. Dalam menggunakan aplikasi ini perlu diperhatikan jarak, kemiringan kamera dan focus kamera smartphone dengan marker.

c. Pemanfaatan teknologi ini diharapkan dapat digunakan oleh mahasiswa untuk mengenal model 3D secara interaktif.

\section{DAFTAR PUSTAKA}

[1] Azhar, Nur Fajri.2011 "Pemanfaatan Augmented Reality untuk Game "Ranger Target" FPS Berbasis Android Menggunakan Unity 3D dan Vuforia SDK". Fakultas Teknologi Informasi, Institut Teknologi Sepuluh Nopember.

[2] Ben, Butchart, 2011."Augmented Reality for Smartphones", Apress,

[3] Cawood, Stephen. Fiala, Mark. 2008 "Augmented Reality A Practical Guide". Apress. 